\title{
Abiraterone Acetate and Enzalutamide: Similar Efficacy in Treating Post Docetaxel Metastatic Castration-resistant Prostate Cancer: Single Center Experience
}

\author{
LI-WEN CHANG ${ }^{1}$, SHENG-CHUN HUNG ${ }^{1,2}$, SHIAN-SHIANG WANG ${ }^{1,2,3}$, JIAN-RI LI $^{1,2,4}$, \\ CHENG-KUANG YANG ${ }^{1}$, CHUAN-SHU CHEN ${ }^{1,2}$, HAO-CHUNG HO $^{1}$, \\ CHEN-LI CHENG ${ }^{1,2}$, YEN-CHUAN OU ${ }^{1,2,5,6}$ and KUN-YUAN CHIU ${ }^{1,3}$ \\ ${ }^{1}$ Division of Urology, Department of Surgery, Taichung Veterans General Hospital, Taichung, Taiwan, R.O.C.; \\ ${ }^{2}$ Institute of Medicine, Chung Shan Medical University, Taichung, Taiwan, R.O.C.; \\ ${ }^{3}$ Department of Applied Chemistry, National Chi Nan University, Nantou, Taiwan, R.O.C.; \\ ${ }^{4}$ Department of Medicine and Nursing, Hungkuang University, Taichung, Taiwan, R.O.C.; \\ ${ }^{5}$ Department of Medical Research, Taichung Veterans General Hospital, Taichung, Taiwan, R.O.C.; \\ ${ }^{6}$ Department of Urology, Tungs' Taichung MetroHarbor Hospital, Taichung, Taiwan, R.O.C.
}

\begin{abstract}
Background/Aim: Abiraterone (AA) and enzalutamide (ENZ) were introduced in Taiwan since 2012 for the treatment of patients with post-docetaxel metastatic castration-resistant prostate cancer ( $m C R P C)$. This study aims to retrospectively compare the efficacy of the two regimens. Materials and Methods: The study cohort consisted of 77 $m C R P C$ patients previously treated with docetaxel and subsequently with $A A(n=63$, the AA group) or $\operatorname{ENZ}(n=13$, the ENZ group), all treated in our hospital. Clinical parameters of the two groups were compared to determine differences between pre-treatment variables and treatment outcomes. Results: Sixty-four patients received AA and 13 received ENZ, with a median 18.2 vs. 14.5 months follow-up $(p=0.434)$. Prostate-specific antigen (PSA) response $>50 \%$ was 31 (48.4\%) in AA and 9 (69.2\%) in ENZ ( $p=0.171)$, while $P S A$ response $>90 \%$ was $16(25 \%)$ in $A A$ and $5(38.5 \%)$ in ENZ ( $p=0.32)$. The median progression-free survival (PFS) was 7.3 (95\%CI=4.796-9.804) months in $A A$ and 9.5 months (95\%CI=5.743-13.257) in ENZ ( $p$ of log rank=0.766). The median overall survival (OS) from second-line hormone
\end{abstract}

Human ethical statement: certification of approval with IRB: CE13240A-2

Correspondence to: Kun Yuan Chiu, Division of Urology, Department of Surgery, Taichung Veterans General Hospital, 1650 Sec. 4, Taiwan Boulevard, Taichung 40705, Taiwan, R.O.C. Tel: +886 423741215, Fax: 886 423593160, e-mail: chiu37782002@yahoo.com

Key Words: Abiraterone acetate, enzalutamide, metastatic castrationresistant prostate cancer, prostate-specific antigen (PSA) progression. treatment was 30.2 months in AA group and 16.2 months in ENZ group ( $p$ of log rank=0.734). Neither the uni- nor the multi-variate COX-regression analysis distinguished any advantage of the two-drug regimen in terms of PFS or OS. Metastasis volume $(H R=3.032, \quad 95 \% C I=1.281-7.178$, $p=0.012)$ and nadir PSA $(H R=1.000,95 \% C I=1.000-1.001$, $p=0.010)$ were shown as independent risk factors for the survival of AA/ENZ-treated patients. Conclusion: AA and ENZ had a similar efficacy in treating post-docetaxel $m C R P C$ patients. Metastatic volume and nadir PSA were independent risk factors of these patients in predicting their diseasespecific survival and overall survival.

Metastatic prostate cancer accounts for nearly $30 \%$ of newly diagnosed prostate cancers in Taiwan (1). Currently the standard protocol for treatment is a sequence involving androgen deprivation therapy (ADT), chemotherapy, and medication with androgen receptor signaling inhibitors (2). Abiraterone acetate (AA), a selective inhibitor of cytochrome CYP17 that blocks androgen synthesis in the adrenal gland, testis and prostate tumor (3), has demonstrated therapeutic efficacy in treating chemo-naïve or post-chemotherapy metastatic castration-resistant prostate cancer (mCRPC) $(4,5)$. Enzalutamide (ENZ), an androgen-receptor inhibitor that blocks the translocation of androgen-receptor to cell nucleus and its binding with DNA (6), has also proven efficacy in both setting of mCRPC with AFFIR and PREVAIL trial $(7,8)$.

Docetaxel, AA, and ENZ are often used to treat mCRPC at different courses of the disease, and all have tolerable side effects along with convenient outpatient therapy $(4,5,7,8)$. Determining the best treatment sequence is a challenge for clinicians. However, no large-scale clinical trial has yet been 
done to directly compare treatment efficacies of AA and ENZ. In the post-chemotherapy setting, COU-AA-301 trial reported 10.2 months of progression-free survival (PFS) and 14.8 months of overall survival (OS), with a response rate of $38.0 \%$ (4). In contrast, the AFFIRM trial showed a PFS of 8.3 months and OS of 18.4 months, with a $54 \%$ response rate (8). One retrospective study suggested that in treating chemo-naïve mCRPC, AA has a more favorable outcome for PFS but not OS, when compared with ENZ (9). Conflicting results were, however, reported in another meta-analysis study, which suggested that in treating chemo-naïve mCRPC, ENZ, rather than AA, yields a better PFS, while finding no difference between the two drugs in the post-chemo setting (10). Cross resistance may exist in mCRPC patients. For example, ENZ shows antitumor effects after AA fails, while AA has less antitumor effects after ENZ fails (1113). Both AA and ENZ, with similar action target for mCRPC (i.e., the androgen-signaling pathway), have demonstrated clinical benefits, treatment efficacy and adverse effect tolerability in chemo-naïve, as well as in post-chemotherapy settings. Only the additional use of prednisolone, if applicable, would be another factor to consider in the choice between AA and ENZ for the treatment (14).

Herein, we conducted a retrospective study and clinical investigation to determine the treatment efficacy of AA and ENZ in post-docetaxel mCRPC patients and validated several clinical factors correlated with PFS and OS before treatment.

\section{Patients and Methods}

Patients. From April 2012 to January 2018 we studied a total of 77 mCRPC patients under treatment at Taichung Veteran General Hospital. They all had prior treatment-failure with docetaxel. Other patients who had been treated with carbazitaxel or other chemotherapy were excluded. Of these 77 patients, 64 subsequently received AA (the AA group) and 13 received ENZ (the ENZ group). Treatment regimens were (a) AA: $1,000 \mathrm{mg}$ plus prednisolone 5 or $10 \mathrm{mg}$ once daily or (b) ENZ: $160 \mathrm{mg}$, in combination with persisted ADT. Written informed consents were obtained from each patient before study. Our protocol was approved by the Institute Review Board of Taichung Veterans General Hospital, number CE13240A-2.

Clinical-pathological evaluation. The development of mCRPC was characterized based on imaging studies, and the metastasis of disease was confirmed by computer tomography (CT) or bone scan, as well as the following indications: a continuous rise of serum prostatespecific antigen (PSA) levels, the progression of pre-existing disease, and/or the appearance of new metastases under castration levels of testosterone $(<50 \mathrm{ng} / \mathrm{dl})$. Metastatic volume was categorized and defined by the presence of visceral metastases, or $\geq 4$ bone lesions with $\geq 1$ locations outside the vertebral bodies and pelvis. The endpoint evaluation was PSA progression, as defined according to the criteria outlined in the Prostate Cancer Working Group second publication (PCWG2): i.e., first PSA increase that is $\geq 25 \%$ and $\geq 2$ $\mathrm{ng} / \mathrm{ml}$ above the nadir, and which is confirmed by a second value $\geq 3$ weeks later (15) and OS, defined as all cause deaths.
Statistical analysis. The Mann-Whitney $U$-test and Fisher's exact $t$ test were used for comparing continuous variables, and $\chi^{2}$ test was used for categorical variables. Kaplan-Meier survival curve with log-rank test was used to evaluate the OS and for inter-group comparisons. All statistical tests were done using IBM SPSS version 22 for Windows (SPSS, Chicago, IL, USA), and $p$-values $<0.05$ were considered significant differences.

\section{Results}

Median age for each group was 67.5 years old (IQR=61.2573.75) for AA, and 71.0 years old (IQR=60.50-78.50) for ENZ $(p=0.718)$. The median initial PSA were $112.50 \mathrm{ng} / \mathrm{ml}$ (IQR $39.73-450.75)$ for $\mathrm{AA}$, and $284.00 \mathrm{ng} / \mathrm{ml}$ (83.49-723.85) for ENZ ( $p=0.395)$. Both groups had similar hormone-sensitive periods (AA vs. ENZ: $20.00 v s .18 .00$ months, $p=0.718$ ) and docetaxel cycles (AA vs. ENZ: $75 \mathrm{mg}: 5$ vs. 6 months, $p=0.835 ; 50 \mathrm{mg}: 7$ vs. 12.5 months, $p=0.056$ ).

The group median PSA levels (before AA/ENZ) were $19.52 \mathrm{ng} / \mathrm{ml} \quad(\mathrm{IQR}=16.25-124.38)$ for $\mathrm{AA}$, and 8.42 $(\mathrm{IQR}=1.17-24.81)$ for ENZ $(p=0.242)$. High volume metastases were similar in the two groups $(54.70 \%$ for AA, and $61.50 \%$ for ENZ, $p=0.65$ ). After medication, PSA levels declined to $36.95 \%$ in the AA group and $77.79 \%$ in the ENZ group $(p=0.103)$. Although PSA response rate appeared better in the ENZ group, the inter-group difference was not statistically significant (AA vs. ENZ: PSA response $>50 \%$ : $48.40 \%$ vs. $69.20 \%, p=0.171$ ); PSA response $>90 \%: 25 \%$ vs. $38.5 \%, p=0.320$ ) (Table I, Figure 1).

Among all patients, 57 in the AA group suffered from PSA progression compared to 9 in the ENZ group (Figure 2A). The median time to PSA progression was 7.3 months for AA, and 9.5 months for ENZ. Figure 2B shows temporal changes of their overall survivals. Among all patients, 29 in the AA group and 6 in the ENZ group expired (with the median duration to OS at 30.2 months for AA, and 16.2 months for ENZ).

Cox regression and multivariate adjusted harzard ratio (HR) model was further used to evaluated the risk of PFS and OS. After multivariate adjustment, hormone sensitive period $(\mathrm{HR}=0.989,95 \% \mathrm{CI}=0.978-1.000, p=0.046)$, high volume metastasis (HR=2.431, 95\% CI 0.372-4.308, $p=0.002)$, and nadir PSA after drug $(\mathrm{HR}=1.000$, $95 \% \mathrm{CI}=1.000-1.001, p=0.020)$ were independent risk factors of PSA progression after second line hormone therapy (Table II). Furthermore, high volume metastasis ( $\mathrm{HR}=3.032$, 95\% CI $=1.281-7.178, p=0.012)$ and nadir PSA after the medication $(\mathrm{HR}=1.000,95 \% \mathrm{CI}=1.000-1.001, p=0.010)$ were independent risk factors of overall survival after second line hormone therapy (Table III).

Adverse events of medication are summarized in Table IV. Two patients in the AA group were withdrawn before the end of study due to Grade 3/4 liver function impairment, and two in the ENZ group had withdrawn due to Grade 3/4 fatigue. No seizure was observed in any of the patients. 
Table I. Basic characteristics of patients who received abiraterone acetate and enzalutamide.

\begin{tabular}{|c|c|c|c|c|c|c|}
\hline & & Abirater & one $(n=64)$ & Enzalutan & ide $(n=13)$ & \\
\hline & & Median or $\mathrm{n}$ & (IQR) or \% & Median or $\mathrm{n}$ & IQR or $\%$ & $p$-Value \\
\hline Age & & 67.5 & $(61.25-73.75)$ & 71,00 & $(60.50-78.50)$ & 0.718 \\
\hline Performance status (ECOG) & 1 & $(0-1)$ & 1 & $(0-1)$ & 0.988 & \\
\hline Hypertension & & 31 & 48.4 & 6 & 46.2 & 0.881 \\
\hline Diabetes & & 11 & 17.2 & 3 & 23.1 & 0.616 \\
\hline Coronary artery disease & & 8 & 12.5 & 1 & 7.7 & 0.623 \\
\hline Radical prostatectomy & & 10 & 15.6 & 1 & 7.7 & 0.456 \\
\hline Radiation therapy & & 16 & 25,00 & 2 & 15.4 & 0.455 \\
\hline Initial PSA & & 112.5 & $(39.73-450.75)$ & 284 & $(83.49-723.85)$ & 0.395 \\
\hline Gleason score & & 9 & $(7-9)$ & 9 & $(8-9.5)$ & 0.438 \\
\hline Hormone therapy period & & 20 & $(10-38.5)$ & 18 & $(10.50-34.50)$ & 0.718 \\
\hline Metastasis & Viseral & 13 & 20.3 & 3 & 23.1 & 0.823 \\
\hline & Lung & 7 & 10.9 & 2 & 15.4 & 0.649 \\
\hline & Liver & 2 & 3.1 & 1 & 7.7 & 0.438 \\
\hline & Bone & 64 & 100 & 13 & 100 & \\
\hline & High volume & 35 & 54.7 & 8 & 61.5 & 0.650 \\
\hline & Low volume & 29 & 45.3 & 5 & 38.5 & \\
\hline Taxotere & Age & 72.5 & $(64.25-79.00)$ & 72,00 & $(62.50-80.50)$ & 0.849 \\
\hline & $\mathrm{Hb}$ & 12,00 & $(10.30-12.60)$ & 12.85 & $(11.75-13.48)$ & 0.063 \\
\hline & Albumin & 4.1 & $(3.80-4.30)$ & 4.1 & $(4.0-4.1)$ & 0.563 \\
\hline & Alk-P & 118,00 & $(86.25-273.00)$ & 156,00 & $(135.50-374.00)$ & 0.224 \\
\hline & LDH & 216,00 & $(190.00-253.00)$ & 228,00 & $(205.00-296.50)$ & 0.448 \\
\hline & PSA before drug & 27.48 & $(9.34-119.75)$ & 17.14 & $(8.27-82.05)$ & 0.422 \\
\hline & Best PSA & 9.98 & $(3.58-54.27)$ & 7.7 & $(2.85-18.57)$ & 0.523 \\
\hline & PSA decline (\%) & -57.26 & $(-86.68--8.85)$ & $-26,00$ & $(-89.13-5.39)$ & 0.967 \\
\hline & PSA response & 46 & 71.9 & 10 & 76.9 & 0.709 \\
\hline & PSA response $>50 \%$ & 33 & 51.6 & 6 & 46.2 & 0.722 \\
\hline & PSA response $>90 \%$ & 13 & 20.3 & 3 & 23.1 & 0.823 \\
\hline & Taxotere $75 \mathrm{mg}$ & 53 & 82.8 & 9 & 69.2 & 0.260 \\
\hline & Cycle & 5 & $(3-9)$ & 6 & $(2.75-8.25)$ & 0.835 \\
\hline & Taxotere $50 \mathrm{mg}$ & 11 & 17.2 & 4 & 30.8 & 0.260 \\
\hline & cycle & 7 & $(3.3-9.3)$ & 12.5 & $(8.5-20.25)$ & 0.056 \\
\hline 2nd line hormone therapy & Age & 74,00 & $(65.00-80.00)$ & 74,00 & $(64.00-82.00)$ & 0.935 \\
\hline & $\mathrm{Hb}$ & 11.1 & $(10.08-12.20)$ & 12,00 & $(9.95-12.70)$ & 0.301 \\
\hline & Albumin & 3.7 & $(3.38-4.20)$ & 3.6 & $(3.5-3.6)$ & 0.953 \\
\hline & ALK-P & 129,00 & $(79-209.5)$ & 120,00 & $(94.00-221.00)$ & 0.612 \\
\hline & LDH & 257,00 & $(191.50-319.50)$ & 228,00 & $(172.00-293.00)$ & 0.823 \\
\hline & PSA before Drug & 45.3 & $(16.25-124.38)$ & 24.38 & $(8.85-90.42)$ & 0.242 \\
\hline & Best PSA & 19.52 & $(3.18-92.85)$ & 8.42 & $(1.17-24.81)$ & 0.133 \\
\hline & PSA decline (\%) & -36.95 & $(-90.29-78.69)$ & -77.79 & $(-93.44--15.96)$ & 0.103 \\
\hline & PSA response & 35 & 54.7 & 10 & 76.9 & 0.138 \\
\hline & PSA response $>50 \%$ & 31 & 48.4 & 9 & 69.2 & 0.171 \\
\hline & PSA response $>90 \%$ & 16 & 25,00 & 5 & 38.5 & 0.320 \\
\hline & Drug Duration & 7.5 & $(3.25-18.00)$ & 7 & $(4.50-9.50)$ & 0.668 \\
\hline Subsequent therapy & & & & & & \\
\hline Abiraterone & Number & & & 1 & & \\
\hline & Response & & & 0 & 0,00 & \\
\hline & Best decline (\%) & & & 98.72 & & \\
\hline & Duration & & & 6 & & \\
\hline Enzalutamide & Number & 11 & & & & \\
\hline & Response & 7 & 63.6 & & & \\
\hline & PSA decline (\%) & -12.81 & 81.71 & & & \\
\hline & Best decline (\%) & -99.72 & & & & \\
\hline & Duration & 8 & 6.573 & & & \\
\hline Docetaxel rechallenge & Number & & & & & \\
\hline & Dosage $75 \mathrm{mg}$ & 3 & & 1 & & \\
\hline & Dosage $50 \mathrm{mg}$ & 0 & & 1 & & \\
\hline & Response & 1 & 33.33 & 2 & 100,00 & \\
\hline & Best decline (\%) & -22.37 & & -25.33 & & \\
\hline Median follow-up time from mCRPC & & 31.45 & $(31.6-51.9)$ & 24.9 & $(20.10-37.35)$ & 0.231 \\
\hline Median follow-up time from & & 18.2 & $(6.43-26.85)$ & 14.5 & $(7.85-17.80)$ & 0.434 \\
\hline
\end{tabular}

Continuous variable analysis using the Mann-Whitney $U$-test and Fisher's exact test $t$-test. Categorical variables analysis using the Pearson ChiSquare test. $* p<0.05$. PSA, Prostate-specific antigen; Hb, hemoglobin; Alk-P, alkaline phosphatase; LDH, lactic dehydrogenase; mCRPC, metastastic castration-resistant prostate cancer. 
A

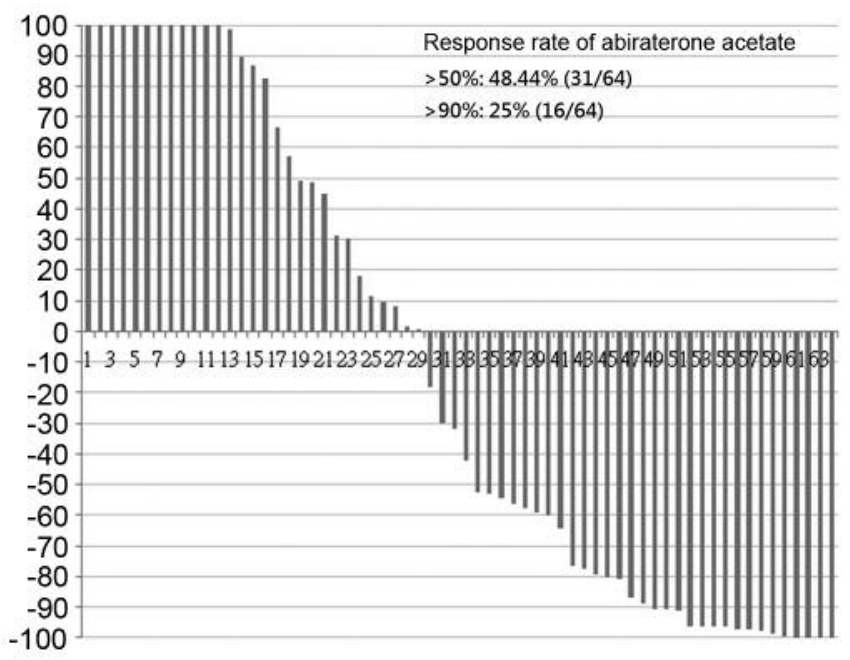

B

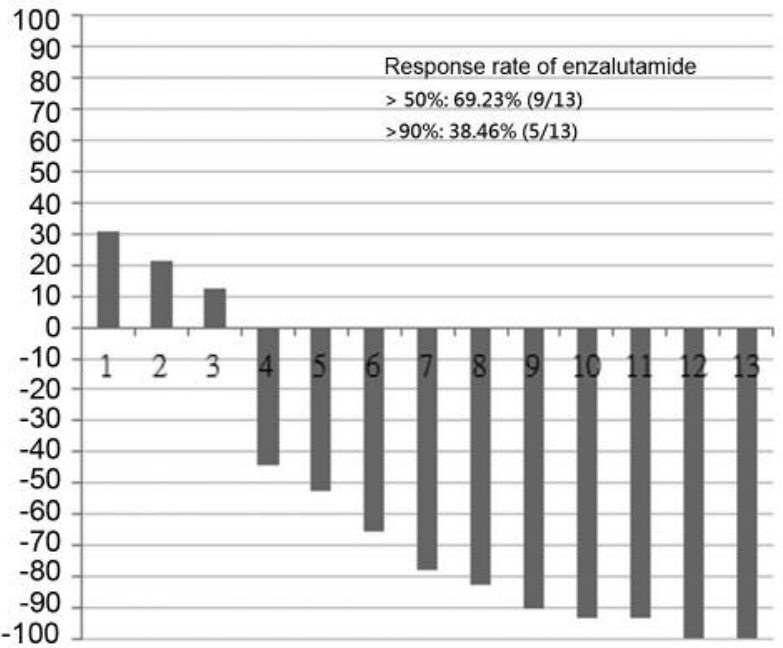

Figure 1. Response rate of abiraterone acetate (AA) and enzalutamide (ENZ) in mCRPC patients after docetaxel. Bar charts show PSA response rate for each patient in the AA group (A) and the ENZ group (B). PSA response rate $>50 \%$ was $48.44 \%$ and $69.23 \%$, while $P S A$ response $>90 \%$ was $25 \%$ and $38.46 \%$, in patients receiving $A A$ or ENZ, respectively.

A

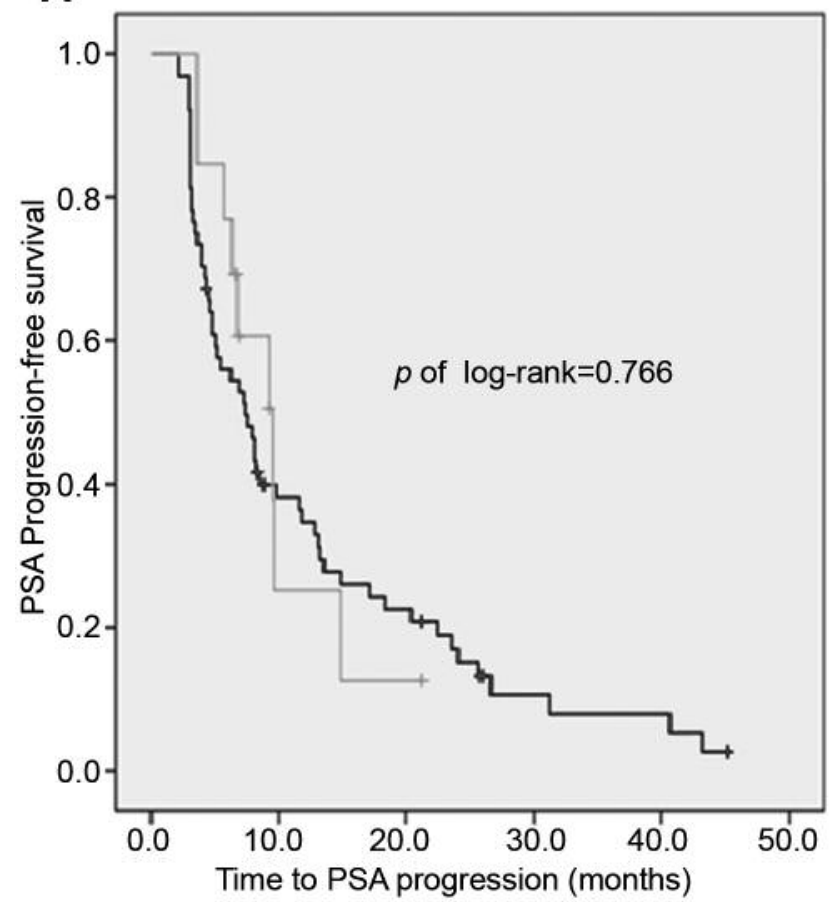

B

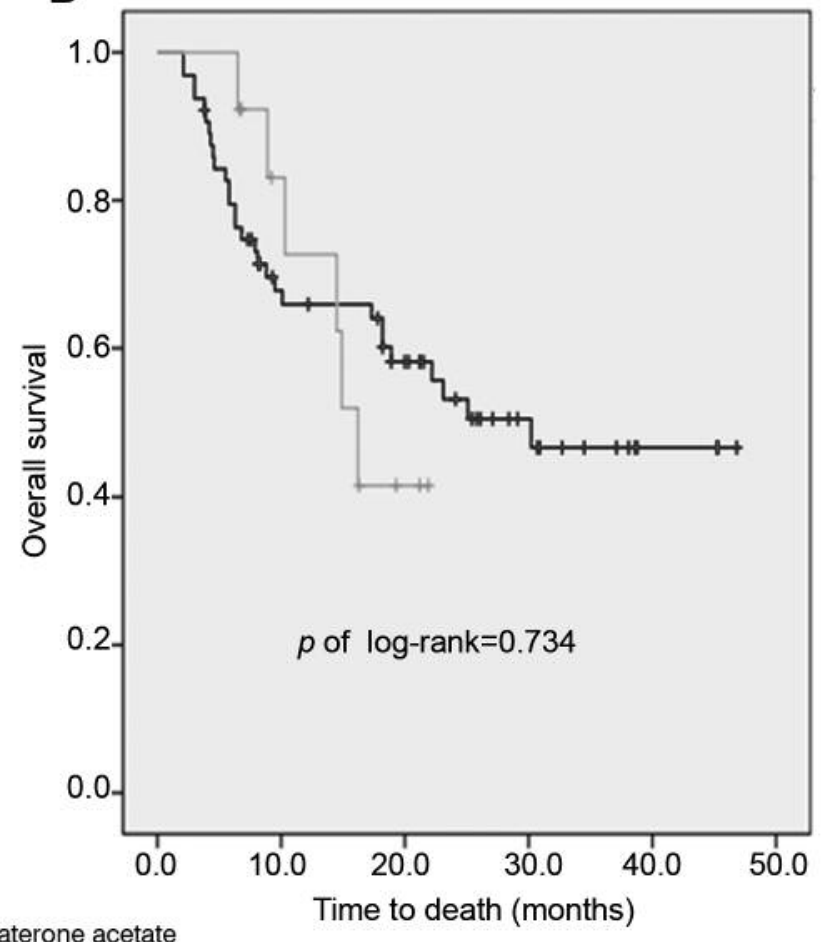

Abiraterone acetate $\sim$ Enzalutamide

Figure 2. Prostate-specific antigen (PSA) progression-free survival (PFS) and overall survival $(O S)$ in mCRPC patients treated with abiraterone acetate (AA) or enzalutamide (ENZ) after docetaxel. Median PFS was 7.3 months in the AA group and 9.5 months in the ENZ group ( $p$ of log rank=0.766) (A). Median OS was 30.2 months in the AA group and 16.2 months in the ENZ group (p of log rank=0.734) (B). 
Table II. Univariate and multivariate Cox proportional hazard regression analysis for prediction of disease progression.

\begin{tabular}{|c|c|c|c|c|}
\hline \multirow[b]{2}{*}{ Covariate } & \multicolumn{2}{|c|}{ Univariate analysis } & \multicolumn{2}{|c|}{ Multivariate analysis } \\
\hline & HR (95\%CI) & $p$-Value & HR (95\%CI) & $p$-Value \\
\hline Performance status & $1.329(0.921-1.917)$ & 0.128 & & \\
\hline Age & $1.004(0.973-1.036)$ & 0.813 & & \\
\hline Hypertension & $1.098(0.666-1.810)$ & 0.715 & & \\
\hline Diabetes & $0.839(0.447-1.575)$ & 0.584 & & \\
\hline Coronary artery disease & $1.298(0.613-2.748)$ & 0.495 & & \\
\hline Radical prostatectomy & $1.513(0.763-3.000)$ & 0.236 & & \\
\hline Radiation therapy & $1.204(0.683-2.122)$ & 0.52 & & \\
\hline Initial PSA & $1.000(1.000-1.000)$ & 0.816 & & \\
\hline Gleason score & $1.158(0.930-1.443)$ & 0.19 & & \\
\hline Hormone sensitive period & $0.986(0.975-0.997)$ & $0.011 *$ & $0.989(0.978-1.000)$ & $0.046^{*}$ \\
\hline \multicolumn{5}{|l|}{ Metastatic volume } \\
\hline Low & Reference & & Reference & \\
\hline High & $2.793(1.610-4.845)$ & $0.000^{*}$ & $2.431(1.372-4.308)$ & $0.002 *$ \\
\hline Taxotere cycle & $0.958(0.915-1.002)$ & 0.063 & & \\
\hline $\mathrm{Hb}$ before drug & $0.920(0.792-1.069)$ & 0.275 & & \\
\hline Albumin before drug & $0.437(0.093-2.058)$ & 0.295 & & \\
\hline Alk-P before drug & $1.001(0.999-1.003)$ & 0.464 & & \\
\hline LDH before drug & $1.001(1.000-1.003)$ & 0.133 & & \\
\hline PSA before drug & $1.001(1.000-1.001)$ & $0.018^{*}$ & $1.000(0.999-1.001)$ & 0.897 \\
\hline Nadir PSA after drug & $1.000(1.000-1.001)$ & $0.000 *$ & $1.000(1.000-1.001)$ & $0.020 *$ \\
\hline \multicolumn{5}{|l|}{ 2nd line hormone therapy } \\
\hline Abiraterone & Reference & & & \\
\hline Enzalutamide & $0.898(0.439-1.838)$ & 0.769 & & \\
\hline
\end{tabular}

Cox regression with multivariate adjustment. ${ }^{*} p<0.05$. HR, Hazard ratio; CI, confidence interval; PSA, prostatic-specific antigen; Hb, hemoglobin; Alk-P, alkaline phosphatase; LDH, lactic dehydrogenase.

\section{Discussion}

This study, through data analysis based on retrospective chart reviews in a single medical center, revealed no difference between the efficacy of AA and ENZ in treating mCRPC patients after the docetaxel failure. ENZ, compared with AA, appeared to be slightly better in preserving the PSA response rate and PSA decline, but the differences were not statistically significant in terms of PFS and OS.

Several studies reported that ENZ provides a better PSA response rate and PFS in treating mCRPC patients. Fang et al. in a trial-level meta-analysis, showed that OS was increased by 8.3 months in the pre-docetaxel setting, and by 2.2 months in post-docetaxel setting, in ENZ-treated mCRPC patients, compared to the respective AA-groups; however, differences did not reach statistical significance (10). In another network meta-analysis, Kang et al. also suggested that ENZ was the most effective agent in improving OS $(\mathrm{HR}=0.71)$, and AA seemed to be less effective compared to ENZ $(H R=0.78)$. Such report was however, based on pooled data analysis, and differences between the pre- and postchemotherapy settings were neglected (16). A pooled data analysis of major phase III clinical trials COU-AA-301, COU-AA-302, PREVAIL and AFFIRM yielded similar but less significant results; particularly it suggested that ENZ may be superior to AA only with respect to radiographic PFS, but not to OS, in both pre- and post- docetaxel settings (17). Consequently, pairwise meta-analysis of randomized controlled trials revealed that the use of novel AR pathwaytargeted agents reduced the risk of death as well as the risk of disease progression in $21 \%$ and $52 \%$ of mCRPC patients, respectively (18).

Cross-resistance between the different regimens in mCRPC has been observed in literature indicating that sensitivity to one compound is impaired by another with a similar or overlapping mechanism of action (19). Moughan et al. using a retrospective study, compared the sequences 'AA-to-ENZ' and 'ENZ-to-AA' in $\mathrm{MCRPC}$ patients, and found that the former sequence had better PFS (HR=0.37, $p<0.001)$ (20). More specifically, response of ENZ after AA failure was higher compared to that of AA after ENZ failure (37\% vs. 13\%) (20). Another study by Terada et al., investigated AA-to-ENZ versus ENZ-to-AA in Asian CRPC patients and revealed an advantage favoring ENZ in the second-line setting $(\mathrm{HR}=0.67, p=0.009)$ compared $\mathrm{t} o$ AA (21). Similar results were shown in a randomized phase II cross-over study in mCRPC patients, in which first-line ENZ was associated with a better response rate compared to AA, while no difference in time to PSA progression was found (12). 
Table III. Univariate and multivariate Cox proportional hazard regression analysis for prediction of overall survival.

\begin{tabular}{|c|c|c|c|c|}
\hline \multirow[b]{2}{*}{ Covariate } & \multicolumn{2}{|c|}{ Univariate } & \multicolumn{2}{|c|}{ Multivariate } \\
\hline & HR $(95 \% \mathrm{CI})$ & $p$-Value & HR $(95 \% \mathrm{CI})$ & $p$-Value \\
\hline Performance status & $2.123(1.262-3.572)$ & $0.005^{*}$ & $1.703(0.977-2.970)$ & 0.061 \\
\hline Age & $1.009(0.967-1.054)$ & 0.666 & & \\
\hline Hypertension & $0.914(0.460-1.816)$ & 0.797 & & \\
\hline Diabetes & $0.564(0.198-1.609)$ & 0.284 & & \\
\hline Coronary artery disease & $1.478(0.568-3.849)$ & 0.423 & & \\
\hline Radical prostatectomy & $1.861(0.801-4.323)$ & 0.149 & & \\
\hline Radiation therapy & $1.368(0.633-2.957)$ & 0.425 & & \\
\hline Initial PSA & $0.999(0.998-1.000)$ & 0.072 & & \\
\hline Gleason score & $1.068(0.787-1.451)$ & 0.672 & & \\
\hline Hormone sensitive period & $0.989(0.974-1.004)$ & 0.161 & & \\
\hline \multicolumn{5}{|l|}{ Metastatic volume } \\
\hline Low & Reference & & Reference & \\
\hline High & $3.776(1.627-8.764)$ & $0.002 *$ & $3.032(1.281-7.178)$ & $0.012 *$ \\
\hline Taxotere cycle & $0.967(0.903-1.036)$ & 0.338 & & \\
\hline $\mathrm{Hb}$ before drug & $0.836(0.679-1.028)$ & 0.089 & & \\
\hline Alk-P before drug & $0.998(0.994-1.003)$ & 0.417 & & \\
\hline LDH before drug & $1.002(1.000-1.005)$ & 0.059 & & \\
\hline PSA before drug & $1.000(1.000-1.001)$ & 0.382 & & \\
\hline Nadir PSA after drug & $1.000(1.000-1.001)$ & $0.002 *$ & $1.000(1.000-1.001)$ & $0.010^{*}$ \\
\hline \multicolumn{5}{|l|}{ 2nd line Hormone therapy } \\
\hline Abiraterone & Reference & & & \\
\hline Enzalutamide & $1.168(0.477-2.860)$ & 0.735 & & \\
\hline
\end{tabular}

Cox regression with multivariate adjustion. ${ }^{*} p<0.05$. HR, Hazard ratio; CI, confidence interval; PSA, prostatic specific antigen; Hb, hemoglobin; Alk-P, alkaline phosphatase; LDH, lactic dehydrogenase.

Table IV. Adverse events of abiraterone and enzalutamide.

\begin{tabular}{lcccc}
\hline & \multicolumn{2}{c}{ Abiraterone acetate (n=64) } & \multicolumn{2}{c}{ Enzalutamide (n=13) } \\
\cline { 2 - 3 } Adverse events & Grade $1 / 2(\mathrm{n})$ & Grade 3/4 (n) & Grade 1/2 (n) & Grade 3/4 (n) \\
\hline Anemia & 1 & 1 & 4 & 0 \\
Fatigue & 2 & 0 & 2 & 0 \\
Nausea & 1 & 0 & 1 & 0 \\
Constipation & 1 & 0 & 1 & 0 \\
Diarrhea & 1 & 0 & 0 & 0 \\
Hypertension & 4 & 0 & 0 & 0 \\
Peripheral Edema & 2 & 0 & 0 & 0 \\
Hot flush & 0 & 0 & 0 & 0 \\
Electrolyte Imbalance & 4 & 0 & 0 & 0 \\
Elevated ALT & 1 & 2 & 0 & 0 \\
Seizure & 0 & 0 & 0 & 0 \\
Vertigo & 1 & 0 & 0 & 0 \\
Stasis Dermatitis & 2 & 0 & 0
\end{tabular}

ALT, Alanine aminotransferase.

One possible explanation on the observed efficacy of ENZ after AA failure is the increased expression levels of AR after AA treatment, as demonstrated in the model of mouse-bearing human prostate cancer tumor cells, since ENZ is known to be effective in CRPC with increased AR expression $(22,23)$. In terms of the mechanisms underlying drug actions, AA is known to specifically inhibit two enzymes $(17 \alpha$-hydroxylase and C17,20-lyase) that are necessary for testosterone synthesis from cholesterol precursors in the testis, adrenal gland, and prostatic cancer tissues. The result is a reduction in the circulating 
testosterone level (24). In contrast, ENZ selectively inhibits AR activities by interfering nuclear translocation and impeding DNA binding to androgen response elements and co-activator recruitment as well. ENZ may therefore have selective actions exceeding AA on the androgen receptor signaling pathways (6).

In contrast to COU-AA-301 and AFFIRM trials, our results revealed similar PFS in AA and ENZ second-line treatment in mCRPC patients. On the other hand, OS was longer in the AA group (14.8 months vs. 30.2 months) in compared with COUAA-301 $(4,8)$. However, this may be due to the relative small number of patients in the ENZ group; an extreme value may cause the survival prediction to shift right.

Regarding treatment efficacy of second-line hormonal therapy, several factors are known as predictors, including the AR splice variant-7 mRNA, which is likely involved in the mechanism of drug-resistance (25). Although we did not examine this factor, other clinical factors appeared useful in predicting disease prognosis. Specifically, high volume metastasis predicted poor prognosis in terms of PSA progression and OS. This finding is consistent with what was known in the CHAARTED trial; high volume metastatic disease was associated with better chemotherapy response rate, compared to low volume metastatic disease in hormonal sensitive prostate cancer patients (26). Moreover, we showed that nadir PSA after novel androgen target agents is another predicting factor of the prognosis. Miyake et al. suggested that patients with docetaxel-naïve mCRPC as well as those who require longer time to reach PSA nadir under AA treatment show better control of the disease (27).

One important limitation of our study is its retrospective design and sample size. Therefore, clinical application of our results would require further randomized control studies with larger sample sizes. A second limitation is that patient numbers are rather different between the two groups, and therefore the power of statistics is weakened. The reason of this bias is that AA was approved for use in Taiwan earlier than ENZ for such treatments; hence, more patients were under AA treatment. Finally, due to the relatively short follow-up periods in the ENZ group, inter-group comparison was difficult.

\section{Conclusion}

Both regimens AA and ENZ had similar treatment efficacy in post-docetaxel mCRPC patients. Metastatic tumor volume and nadir PSA were independent risk factors in predicting the prognosis of progression in terms of free survival and overall survival.

\section{Authors' Contributions}

LW Chang drafted this manuscript. SC Hung and KY Chiu designed this study and collected clinical data. LW Chang and SC Hung encountered statistical analysis and figure drafting. LW Chang, SC Hung, SS Wang, JR Li, CK Yang, CS Chen, HC Ho, CL Cheng, YC
Ou and KY Chiu contribute to all patients' clinical care and follow up. All authors read and approved the final manuscript.

\section{Conflicts of Interest}

The contributing Authors have no conflicts of interest, including specific financial interests or relationships and affiliations relevant to the subject matter or materials discussed in the manuscript.

\section{References}

1 Hung CF, Yang CK and Ou YC: Urologic cancer in Taiwan. Jpn J Clin Oncol 46(7): 605-609, 2016. PMID: 27052114. DOI: 10.1093/jjco/hyw038

2 Lorente D, Mateo J, Perez-Lopez R, de Bono JS and Attard G: Sequencing of agents in castration-resistant prostate cancer. Lancet Oncol 16(6): e279-292, 2015. PMID: 26065613. DOI: 10.1016/S1470-2045(15)70033-1

3 Attard G, Belldegrun AS and de Bono JS: Selective blockade of androgenic steroid synthesis by novel lyase inhibitors as a therapeutic strategy for treating metastatic prostate cancer. BJU Int 96(9): 1241-1246, 2005. PMID: 16287438. DOI: 10.1111/ j.1464-410X.2005.05821.x

4 de Bono JS, Logothetis CJ, Molina A, Fizazi K, North S, Chu L, Chi KN, Jones RJ, Goodman OB Jr, Saad F, Staffurth JN, Mainwaring P, Harland S, Flaig TW, Hutson TE, Cheng T, Patterson H, Hainsworth JD, Ryan CJ, Sternberg CN, Ellard SL, Fléchon A, Saleh M, Scholz M, Efstathiou E, Zivi A, Bianchini D, Loriot Y, Chieffo N, Kheoh T, Haqq CM, Scher HI and COUAA-301 Investigators: Abiraterone and increased survival in metastatic prostate cancer. N Engl J Med 364(21): 1995-2005, 2011. PMID: 21612468. DOI: 10.1056/NEJMoa 1014618

5 Ryan CJ, Smith MR, de Bono JS, Molina A, Logothetis CJ, de Souza P, Fizazi K, Mainwaring P, Piulats JM, Ng S, Carles J, Mulders PF, Basch E, Small EJ, Saad F, Schrijvers D, Van Poppel H, Mukherjee SD, Suttmann H, Gerritsen WR, Flaig TW, George DJ, Yu EY, Efstathiou E, Pantuck A, Winquist E, Higano CS, Taplin ME, Park Y, Kheoh T, Griffin T, Scher HI, Rathkopf DE and COU-AA-302 Investigators: Abiraterone in metastatic prostate cancer without previous chemotherapy. N Engl J Med 368(2): 138-148, 2013. PMID: 23228172. DOI: 10.1056/ NEJMoa1209096

6 Tran C, Ouk S, Clegg NJ, Chen Y, Watson PA, Arora V, Wongvipat J, Smith-Jones PM, Yoo D, Kwon A, Wasielewska T, Welsbie D, Chen CD, Higano CS, Beer TM, Hung DT, Scher HI, Jung ME and Sawyers CL: Development of a second-generation antiandrogen for treatment of advanced prostate cancer. Science 324(5928): 787-790, 2009. PMID: 19359544. DOI: 10.1126/ science. 1168175

7 Beer TM, Armstrong AJ, Rathkopf DE, Loriot Y, Sternberg CN, Higano CS, Iversen P, Bhattacharya S, Carles J, Chowdhury S, Davis ID, de Bono JS, Evans CP, Fizazi K, Joshua AM, Kim CS, Kimura G, Mainwaring P, Mansbach H, Miller K, Noonberg SB, Perabo F, Phung D, Saad F, Scher HI, Taplin ME, Venner PM, Tombal B and PREVAIL Investigators: Enzalutamide in metastatic prostate cancer before chemotherapy. N Engl J Med 371(5): 424433, 2014. PMID: 24881730. DOI: 10.1056/ NEJMoa1405095

8 Scher HI, Fizazi K, Saad F, Taplin ME, Sternberg CN, Miller K, de Wit R, Mulders P, Chi KN, Shore ND, Armstrong AJ, Flaig TW, Fléchon A, Mainwaring P, Fleming M, Hainsworth JD, 
Hirmand M, Selby B, Seely L, de Bono JS and AFFIRM Investigators: Increased survival with enzalutamide in prostate cancer after chemotherapy. N Engl J Med 367(13): 1187-1197, 2012. PMID: 22894553. DOI: 10.1056/NEJMoa1207506

9 Maughan BL, Luber B, Nadal R and Antonarakis ES: Comparing sequencing of abiraterone and enzalutamide in men with metastatic castration-resistant prostate cancer: A Retrospective study. Prostate 77(1): 33-40, 2017. PMID: 27527643. DOI: 10.1002/pros.23246

10 Fang M, Nakazawa M, Antonarakis ES and Li C: Efficacy of abiraterone and enzalutamide in pre- and post-docetaxel castration-resistant prostate cancer: A trial-level meta-analysis. Prostate Cancer 2017: 8560827, 2017. PMID: 29359049. DOI: $10.1155 / 2017 / 8560827$

11 de Bono JS, Chowdhury S, Feyerabend S, Elliott T, Grande E, Melhem-Bertrandt A, Baron B, Hirmand M, Werbrouck P and Fizazi K: Antitumour activity and safety of enzalutamide in patients with metastatic castration-resistant prostate cancer previously treated with abiraterone acetate plus prednisone for $\geq 24$ weeks in Europe. Eur Urol 74(1): 37-45, 2018. PMID: 28844372. DOI: $10.1016 /$ j.eururo.2017.07.035

12 Chi KN, Annala M, Sunderland K, Khalaf D, Finch D, Oja CD, Vergidis J, Zulfiqar M, Beja K, Vandekerkhove G, Gleave M and Wyatt W: A randomized phase II cross-over study of abiraterone + prednisone $(\mathrm{ABI})$ vs enzalutamide (ENZ) for patients (pts) with metastatic, castration-resistant prostate cancer (mCRPC). J Clin Oncol 35(15_suppl): 5002-5002, 2017. DOI: 10.1200/ JCO.2017.35.15_suppl.5002

13 Mori K, Kimura T, Onuma H, Kimura S, Yamamoto T, Sasaki H, Miki J, Miki K and Egawa S: Lactate dehydrogenase predicts combined progression-free survival after sequential therapy with abiraterone and enzalutamide for patients with castrationresistant prostate cancer. Prostate 77(10): 1144-1150, 2017. PMID: 28557065. DOI: 10.1002/pros.23373

14 Zhang T, Zhu J, George DJ, Armstrong AJ: Enzalutamide versus abiraterone acetate for the treatment of men with metastatic castration-resistant prostate cancer. Expert Opin Pharmacother 6(4): 473-485, 2015. PMID: 25534660. DOI: 10.1517/14656566. 2015.995090

15 Scher HI, Halabi S, Tannock I, Morris M, Sternberg CN, Carducci MA, Eisenberger MA, Higano C, Bubley GJ, Dreicer R, Petrylak D, Kantoff P, Basch E, Kelly WK, Figg WD, Small EJ, Beer TM, Wilding G, Martin A, Hussain M and Prostate Cancer Clinical Trials Working Group: Design and end points of clinical trials for patients with progressive prostate cancer and castratelevels of testosterone: recommendations of the Prostate Cancer Clinical Trials Working Group. J Clin Oncol 26(7): 11481159, 2008. PMID: 18309951. DOI: 10.1200/JCO.2007.12.4487

16 Kang M, Jeong CW, Kwak C, Ku JH and Kim HH: Comparing the clinical efficacy of abiraterone acetate, enzalutamide, and orteronel in patients with metastatic castration-resistant prostate cancer by performing a network meta-analysis of eight randomized controlled trials. Oncotarget 8(35): 59690-59697, 2017. PMID: 28938672. DOI: 10.18632/oncotarget.17741

17 Chopra A, Georgieva M, Lopes G, Yeo CM and Haaland B: Abiraterone or enzalutamide in advanced castration-resistant prostate cancer: An indirect comparison. Prostate 77(6): 639646, 2017. PMID: 28101887. DOI: 10.1002/pros.23309

18 Roviello G, Sigala S, Sandhu S, Bonetta A, Cappelletti MR, Zanotti L, Bottini A, Sternberg CN, Fox SB and Generali D: Role of the novel generation of androgen receptor pathway targeted agents in the management of castration-resistant prostate cancer: A literature based meta-analysis of randomized trials. Eur J Cancer 61: 111-121, 2016. PMID: 27162152. DOI: 10.1016/j.ejca.2016.04.002

19 van Soest RJ, van Royen ME, de Morrée ES, Moll JM, Teubel W, Wiemer EA, Mathijssen RH, de Wit R and van Weerden WM: Cross-resistance between taxanes and new hormonal agents abiraterone and enzalutamide may affect drug sequence choices in metastatic castration-resistant prostate cancer. Eur J Cancer 49(18): 3821-3830, 2013. PMID: 24200698. DOI: 10.1016/j.ejca.2013.09.026

20 Maughan BL, Luber B, Nadal R and Antonarakis ES: Comparing sequencing of abiraterone and enzalutamide in men with metastatic castration-resistant prostate cancer: A retrospective study. Prostate 77(1): 33-40, 2017. PMID: 27527643. DOI: 10.1002/pros.23246

21 Terada N, Maughan BL, Akamatsu S, Kobayashi T, Yamasaki T, Inoue T, Kamba T, Ogawa $\mathrm{O}$ and Antonarakis ES: Exploring the optimal sequence of abiraterone and enzalutamide in patients with chemotherapy-naïve castration-resistant prostate cancer: The Kyoto-Baltimore collaboration. Int J Urol 24(6): 441-448, 2017. PMID: 28455853. DOI: 10.1111/iju.13346

22 Mostaghel EA, Marck BT, Plymate SR, Vessella RL, Balk S, Matsumoto AM, Nelson PS and Montgomery RB: Resistance to CYP17A1 inhibition with abiraterone in castration-resistant prostate cancer: induction of steroidogenesis and androgen receptor splice variants. Clin Cancer Res 17(18): 5913-5925, 2011. PMID: 21807635. DOI: 10.1158/1078-0432.CCR-11-0728

23 Chen CD, Welsbie DS, Tran C, Baek SH, Chen R, Vessella R, Rosenfeld MG and Sawyers CL: Molecular determinants of resistance to antiandrogen therapy. Nat Med 10(1): 33-39, 2004. PMID: 14702632. DOI: $10.1038 / \mathrm{nm} 972$

24 Attard G, Reid AH, Olmos D and de Bono JS: Antitumor activity with CYP17 blockade indicates that castration-resistant prostate cancer frequently remains hormone driven. Cancer Res 69(12): 4937-4940, 2009. PMID: 14702632. DOI: $10.1038 / \mathrm{nm} 972$

25 Antonarakis ES, Lu C, Wang H, Luber B, Nakazawa M, Roeser JC, Chen Y, Mohammad TA, Chen Y, Fedor HL, Lotan TL, Zheng Q, De Marzo AM, Isaacs JT, Isaacs WB, Nadal R, Paller CJ, Denmeade SR, Carducci MA, Eisenberger MA and Luo J: AR-V7 and resistance to enzalutamide and abiraterone in prostate cancer. N Engl J Med 371(11): 1028-1038, 2014. PMID: 25184630. DOI: 10.1056/NEJMoa1315815

26 Sweeney CJ, Chen YH, Carducci M, Liu G, Jarrard DF, Eisenberger M, Wong YN, Hahn N, Kohli M, Cooney MM, Dreicer R, Vogelzang NJ, Picus J, Shevrin D, Hussain M, Garcia JA and DiPaola RS: Chemohormonal therapy in metastatic hormone-sensitive prostate cancer. N Engl J Med 373(8): 737746, 2015. PMID: 26244877. DOI: 10.1056/NEJMoa1503747

27 Miyake H, Hara T, Tamura K, Sugiyama T, Furuse H, Ozono S and Fujisawa M: Independent association between time to prostate-specific antigen (PSA) nadir and PSA progression-free survival in patients with docetaxel-naïve, metastatic castrationresistant prostate cancer receiving abiraterone acetate, but not enzalutamide. Urol Oncol 35(6): 432-437, 2017. PMID: 2818 8090. DOI: $10.1016 /$ j.urolonc.2017.01.006

Received March 7, 2019

Revised March 28, 2019

Accepted April 1, 2019 